\title{
Guiding Principle of Innovation in a Multipurpose Public Health Organization
}

\author{
By Marcelino José Jorge* \\ Maria Inês Fernandes Pimentel ${ }^{\dagger}$ \\ Frederico A. de Carvalho: \\ Patrícia Santos Cavalheiro Silva ${ }^{+}$
}

\begin{abstract}
The strategic positioning of multipurpose public health organizations requires cost effectiveness and innovative dynamism. This study investigates the guiding principles of innovation in the Brazilian Leishmaniases Clinical Research and Surveillance Laboratory at the Evandro Chagas National Institute of Infectious Diseases, Oswaldo Cruz Foundation. It examines three primary issues: cost reduction in healthcare procedures; cost effectiveness in resource distribution among healthcare, teaching, and research activities; and growth in relative technical efficiency within the organization. For the analysis of costs and expenses the Activity-Based Costing approach is adopted, whereas research distribution is analysed using the Spearman Test. Further, overall efficiency is studied through Data Envelopment Analysis. The main findings confirm that organizational innovation is driven by relative growth in technical efficiency. Such observed rationality in decision-making could be perceived as an alternative to the neoclassical hypothesis of short-run firm behavior. As such, the article empirically contributes to existing literature regarding guiding principle of innovation in health organizations.
\end{abstract}

Keywords: Clinical research, Leishmaniasis, Innovation, Activity-Based Costing, Efficiency

\section{Introduction}

The microeconomics of innovation focuses on generating knowledge about a given decision resulting in the pioneering replacement of current techniques by new ones (Rosenberg, 1976). In other words, this stream of research aims to formulate basic guiding principles of innovation (Birkinshaw , Hamel and Mol, 2008) or principles driving innovation (Djellal and Gallouj, 2005). In the public health sector, understanding these concepts potentially facilitates the integration of the various aspects of health-care units functioning into a comprehensive health care model, providing a wide range of services for patients and addressing all their needs (Hasslocher-Moreno et al., 2013). It is argued that the efficiency and strategic positioning of such health-care units,

\footnotetext{
* Coordinator, Laboratory for Research in Economics of Healthcare Organizations, Evandro Chagas National Institute of Infectious Diseases, Oswaldo Cruz Foundation, Brazil.

${ }^{\dagger}$ Research Assistant, Leishmaniases Clinical Research and Surveillance Laboratory, Evandro Chagas National Institute of Infectious Diseases, Oswaldo Cruz Foundation, Brazil.

* Associate Professor, College of Business and Accounting, Federal University at Rio de Janeiro, Brazil.

+ Research Assistant, Laboratory for Research in Economics of Healthcare Organizations, Evandro Chagas National Institute of Infectious Diseases, Oswaldo Cruz Foundation, Brazil.
} 
henceforth referred to as multipurpose public health organizations, depends on their relative performance and effective use of resources (Bisang and Katz, 1995).

Lack of knowledge regarding the primary motivation for stimulating innovations in health organizations (Birkinshaw, Hamel and Mol, 2008) as well as treating the latter chiefly as productive units (Djellal and Gallouj, 2005; Ozcan, 2008) calls for further research on innovation in health. Accordingly, empirical research in this field potentially contributes significantly in the promotion of innovative practices within health-care units.

A case of interest within multipurpose public health organizations is the recent implementation of innovative treatment regimens for cutaneous leishmaniasis (CL), using meglumine antimoniate (MA) which took place in the Leishmaniases Clinical Research and Surveillance Laboratory (LapClin Vigileish) at Evandro Chagas National Institute of Infectious Diseases (INI), Oswaldo Cruz Foundation (Fiocruz). INI is a productive unit comprised by various groups focusing on diagnoses, clinical care, teaching, and research on infectious diseases (such as CL) and incorporating the principles of the comprehensive health care approach. Notably, a phase III clinical trial with MA was implemented in LapClin Vigileish at INI between 2009 and 2015. The trial compared the effectiveness and safety measures of the standard treatment regimen for CL recommended by the Brazilian Ministry of Health to those of alternative schemes using lower doses of MA. The alternatives were tested in order to determine their potential as efficiency-driven innovations with costsaving effects.

The present study tests three hypotheses regarding the guiding principles of innovations adopted in LapClin Vigileish. Concepts taken from the literature on institutional change, as described in the context of the comprehensive health care model, are applied in order to investigate the incentives for innovation in this specific multipurpose public health organization. Additionally, debated issues regarding informational access and conditions of competition are discussed.

The comprehensive health care model addresses developments in health services, on the grounds of contemporary changes in the autonomy of patients, new medical technologies, and lack of formal mechanisms addressing complex ethical problems (Ulloa Gonzalez and Barrantes Monge, 2008). Additionally, the model considers the complex relationships between health professionals and patients. These developments include the promotion of good health behavior and disease prevention and recovery, the precedence of human rights over market relations, the delivery of specialized outpatient medical care, the focus on multidisciplinary work and the social reintegration of the patient.

Existing literature highlights the need for adopting an integral health care approach, meeting the standard criteria for effective interaction between healthcare professionals and patients (Ross, 2009). Additionally, being oriented to social protection, this approach considers not only the expected effect of 
prevention, but also guarantees later care in case of financial difficulties arising from high health costs (Knaul et al., 2012). On the other hand, the main challenge for the operation of an economic organization in a competitive environment is efficient planning of resources use from an economic perspective. Public administration management, for example, is seen as consistent with the principles and policies of economic analysis (La Forgia and Couttolenc, 2008). In particular, the neo-classical profit maximization theory highlights the need for absolute economic efficiency. Consequently, the concept of cost-saving and even cost-minimizing innovations follows directly from the neo-classical approach to guiding principles of innovation.

However, the theory of internal economy of organizations considers the hypothesis of asymmetric information in the interaction between managers and production agents within the organization. According to this new approach, the alternative behavioural hypothesis about cost-minimizing innovation is the orientation towards relative efficiency. Analytical "nonparametric" models, such as Data Envelopment Analysis (DEA), are implemented to test the hypothesis that the organizational desideratum is relative efficiency as emulated by peer performance, rather than absolute efficiency (Mantri, 2008).

Within complex public sector organizations, the co-existence of several internal groups of interest hinders agreements on common goals (Bisang and Katz, 1995). This lack of reference prevents an overall assessment of the organization, especially when not all activities have similar performance levels. This is precisely the case for organizations where multiple activities compete internally for available resources. Inefficiencies due to problems of "mutual adjustment" in the short-run could be attributed to such competition (Mintzberg et al., 2006). Multipurpose public health organizations adopting the comprehensive care approach, such as INI, often find themselves in these situations.

In search for a better summary measure of performance, the concept of an efficiency locus, referred to as the "efficiency frontier" is adopted in existing literature to make comparisons among health care units. Namely, the performance of any productive unit is evaluated based to comparisons with the performance of an equivalent unit belonging to the frontier.

\section{Objectives}

At INI, clinical research on various infectious diseases is organized according to the ccomprehensive health care model approach. Each Integrated Action (IA) of INI pursues innovation in treatment regimens for a particular infectious disease and develops specialized activities accordingly. These may include laboratory diagnosis, clinical care at outpatient clinics, daily hospital care or long-term hospitalization, teaching, and research. Such care is provided by infectious disease specialists and people specialising in fifteen other fields. The diversity of objectives among the different groups leads to problems of coordination and effective internal distribution of resources among competing 
units responsible for the IAs. On the other hand, the need to save resources often drives technological and organizational innovation.

The American tegumentary leishmaniasis (ATL) disease occurs endemically in several regions. Meglumine antimoniate (MA) is one of the first-line drugs used for the treatment of ATL. In Brazil, MA is used in the recommended dose of 10-20 mg of antimony (Sb5+) per kilo of body weight on an daily basis for up to 20 days and a maximum of three ampoules per day (WHO, 2010). Recently, a 30-day, low-dosage scheme (5 mg Sb5+ / kg of body weight / day) has been shown to be effective in the treatment of ATL in LapClin Vigileish (Oliveira-Neto et al., 1997; Schubach et al., 2005). Comparing the levels of effectiveness and safety in the implementation of a phase III clinical trial in the standard regimen and in the alternative, lowdosage regimen offered in LapClin Vigileish (Schubach et al., 2005) could be very informative about issues of effectiveness and, particularly, costminimization. In addition to other effects of treatment effectiveness already addressed in prior studies (Schubach et al., 2005), the innovative combination of specialized resources potentially reduces treatment costs, being a basic criterion in the evaluation of health policy alternatives.

The objective of this study is to evaluate the economic efficiency of the alternative, low-dosage treatment regimen for ATL. Three hypotheses regarding the expected effects on INI expenses are tested. Firstly, the alternative treatment regimen is assumed to be a cost-saving innovation. Secondly, this alternative treatment regimen for ATL is assumed to promote cost effectiveness in distribution of resources among INI activities. Finally, the regimen is expected to significantly improve technical efficiency of LapClin Vigileish functioning as compared to other IAs within the organization.

\section{Methodological Approach}

Testing the first hypothesis requires assessments of micro-level expenses and determination of unit costs, based on the activity-based costing (ABC) approach (Nakagawa, 1994). To test the second hypothesis, the association between expenses and unit costs of each IA of each activity of the IAS is evaluated. This evaluation is conducted using the Spearman Rank Correlation analysis. Defining an "efficiency frontier", using a DEA model (Coelli et al., 1998), allows testing the third hypothesis and highlights the contribution of innovative practices in the mix of inputs and outputs (i.e., laboratory results).

Data for these tests are drawn from three primary sources: namely, the public databases of INI; semi-structured interviews of researchers responsible for INI projects; and a survey on the consumption expenses and materials registered by the Federal Government. By observing annual supply of LapClin Vigileish services, unit costs of diagnostic activities - such as clinical care, teaching, and research - are calculated as average costs. The calculation of average rates is feasible in this case as these activities share common costs, they are subject to nosological contingencies and may evade standard routines. 
Data on production, expenses and permanent materials refers to one-year period, long enough to account for seasonality in spending.

The composition of the INI and Fiocruz general budgets serve as a reference to evaluate relevant expenses at the micro-level, as well as to calculate actual unit costs and annual expenses for each modality of service provided by LapClin Vigileish. Selected inputs for relevant expenses and services include: workforce outsourcing; medication; nourishment; reagents; films and papers for image exams; warehousing; other non-warehouse consumable materials; depreciation of equipment and furniture; telecommunication charges and public servers; scholarship for trainees; expenditures on internal administrative support; sample collection; and campus administration.

The health care unit's preferences regarding the distribution of budget resources among the IAs are assumed to be reflected on the annual expenses for each activity. The evaluation of innovations in health care activities, teaching and research focusing on the ATL treatment offered in LapClin Vigileish is based on this assumption. Further, average unit expenses and actual costs are supposed to reveal cost effectiveness of each IS in using budget funds in the year of the analysis.

Specifically, actual activity costs and annual expenditure per IA could reveal whether greater actual cost of an activity undertaken in one IA corresponds to lower allocation of budget funds compared to funds channelled to other IAs in the year of analysis. The Spearman Rank Correlation coefficient is estimated to identify the nature of existing associations between average unit costs and annual costs in each INI activity in 2009.

Further, maximum production and efficiency frontiers, empirically observed for any Decision Making Unit (DMU) included in the sample, are calculated using data envelopment analysis. This way the hypothesis that under imperfect competition with asymmetric information in the short-run (Romer, 1994), the production unit will attempt to achieve relative technical efficiency, is tested.

The efficiency frontier within a large number of organizations is identified by considering all those organizations which operate under statistically optimal circumstances compared to their competitors. In other words, those units which yield maximum production, as obtained from effective allocation of inputs, are those considered to operate at the efficiency frontier. Following this definition, all such organisations demonstrate unit ratios of output over input. Having identified the optimal organizational units, the relative situation of all those units not belonging to the efficient frontier is observed. Synthesis scores of efficiency are obtained, providing information on the effectiveness of the process during which inputs are turned into outputs.

DEA-BCC-O, a model based on the assumption of product maximization, is applied to analyse short-run efficiency at INI. It should be noted here that INI operates with a pre-set budget while target setting is characterised by asymmetric information (Mantri, 2008). The data envelopment analysis computer program is used to calculate the production frontier of INI's IAs 
(Coelli, 1996). The following eight IAs were sampled for the efficiency survey: chagas disease; acute febrile diseases and dengue (DFA / Dengue); HTLV; Leishmaniases; Mycoses; Toxoplasmosis; Tuberculosis; HIV/AIDS.

A common efficiency frontier for the 64 observations corresponding to the period 2002-2009 is calculated using the DEA computer program. The DEA model is specified with two input resources; namely, the number of hours each doctor worked per year; and the annual operating expenses at current prices. These expenses include medication, reagents, and hospital supplies among others.

Seven types of products are studied annually in order to determine efficiency levels of analysed activities; namely, diagnostic exams; infectious diseases; specialist consultations; number of hospitalization days; published papers; patients participating in the research projects; theses and dissertations; and guided searches in patient medical records.

\section{Results}

Table 1 shows the total and procedure- specific annual expenses between 2006 and 2009, for all patient assistance activities taking place in the LapClin Vigileish unit, according to the appropriation criteria included in INI and Fiocruz budgets (DIE).

Table 2 shows the cost minimization analysis for the expenses included in INI's budget according to the appropriation criterion, as depicted in DE columns. Additionally, table 2 presents the evolution in cost performance of LapClin Vigileish activities between 2006 and 2009.

A strategic feature of cost performance in a multipurpose organization is the allocation of resources used for each activity within the respective management units, with this type of allocation ensuring the efficiency of the organization. Such prevalent trends followed by annual expenses and average unit costs of each IA in INI and its various activities are evaluated for the year 2009. As shown in table 3, negative values of the rank correlation coefficients indicate an inverse association among annual and average expenses. Evidently, more resources appear to be allocated to the IAs with optimal cost performance. 
Table 1. LapClin Vigileish - Diagnosis and Clinical Care Activities - 2006 to 2009

\begin{tabular}{|c|c|c|c|c|c|c|c|c|}
\hline DESCRIPTION & AMOUNT & TYPES & $\begin{array}{c}2006 \\
\text { DIE-YEAR } \\
(*)(* *)\end{array}$ & $\begin{array}{l}\text { DIE/CLINICAL } \\
\text { CARE }(*) \\
\end{array}$ & AMOUNT & TYPES & $\begin{array}{c}2009 \\
\text { DIE-YEAR } \\
(*)(* *)\end{array}$ & $\begin{array}{c}\text { DIE/CLINICAL } \\
\text { CARE (*) } \\
\end{array}$ \\
\hline $\begin{array}{l}\text { Medical appointment - Infectious diseases } \\
\text { specialist }\end{array}$ & 646 & 2 & $241.430,13$ & 79,97 & 485 & 2 & $121.023,97$ & 249,53 \\
\hline Medical appointment - Other specialties & 3793 & 2 & $151.526,90$ & 85,61 & 3300 & 2 & $694.790,25$ & 210,54 \\
\hline Appointments - Other health professionals & 3721 & 2 & $398.297,25$ & 96,21 & 1056 & 2 & $347.484,60$ & 329,06 \\
\hline Outpatients clinic procedures & 7 & 11 & 692,53 & 5,92 & 21 & 9 & 863,69 & 41,13 \\
\hline Nurse procedures & 2701 & 45 & $80.103,41$ & 29,66 & 1666 & 56 & $46.798,17$ & 28,09 \\
\hline Hospital bed-day & 276 & - & $293.717,87$ & $1.064,20$ & 51 & - & $54.142,82$ & $1.061,62$ \\
\hline Hospital bed-day (with meals and medications) & 276 & - & $356.206,09$ & $1.290,60$ & 51 & - & $61.289,27$ & $1.201,75$ \\
\hline Patients to hospital bed-day & 11 & - & $356.206,09$ & $32.382,37$ & 5 & - & $61.289,27$ & $12.257,85$ \\
\hline Daily hospital care & 104 & - & $24.571,50$ & 236,26 & 110 & - & $32.325,15$ & 293,87 \\
\hline Histopathology laboratory & 389 & 9 & $69.247,20$ & 178,01 & 802 & 9 & $64.659,07$ & 80,62 \\
\hline Bacteriology laboratory & 1360 & 22 & $91.331,70$ & 67,16 & 1989 & 17 & $86.361,11$ & 43,42 \\
\hline Transfusional agency & 23 & 3 & $2.098,00$ & 91,22 & 6783 & 3 & - & - \\
\hline Image laboratory & 1019 & 90 & $183.709,89$ & 180,28 & 1271 & 49 & $179.371,48$ & 141,13 \\
\hline Immunodiagnosis laboratory & 374 & 26 & 418,37 & 1,12 & 4563 & 21 & $9.799,13$ & 2,15 \\
\hline Mycology laboratory & 11 & 3 & 995,28 & 90,48 & 2 & 1 & 239,86 & 119,93 \\
\hline Parasitology laboratory & 4361 & 25 & $281.349,28$ & 64,51 & 2163 & 11 & $994.284,65$ & 459,68 \\
\hline Clinical pathology laboratory & 15922 & 65 & $340.642,88$ & 21,39 & 16310 & 26 & $183.131,55$ & 11,23 \\
\hline Zoonotic diseases laboratory & 42 & 3 & $16.431,82$ & 391,23 & 98 & 2 & $88.727,56$ & 905,38 \\
\hline
\end{tabular}

Source: Research results.

(*) In R \$, prices in 2010.

(**) DIE - Expense items with resources included in Fiocruz and INI budgets. 
Table 2. Annual Expenses and Unit Costs per Activity in LapClin Vigileish-2006 to 2009

\begin{tabular}{|c|c|c|c|c|c|}
\hline \multirow{2}{*}{ ACTIVITY } & \multicolumn{2}{|c|}{ DE-YEAR $(*)(* *)$} & \multicolumn{3}{|c|}{ DE/CLINICAL CARE $(*)$} \\
\hline & 2006 & 2009 & 2006 & 2009 & $2009 / 2006$ \\
\hline OUTPATIENT CLINIC & $175.865,85$ & $320.788,70$ & n.a. & n.a. & n.a. \\
\hline Appointment of infectious diseases specialist & $12.767,46$ & $59.975,64$ & 24,10 & 131,84 & INCREASED \\
\hline Medical appointment other specialties & $40.643,25$ & $19.978,72$ & 9,47 & 7,47 & DECREASED \\
\hline Appointments of other health professionals & $88.232,37$ & $215.144,62$ & 32,67 & 232,54 & INCREASED \\
\hline Outpatient clinic procedures & 70,89 & 24,12 & 0,66 & 1,21 & INCREASED \\
\hline Nurse procedures & $34.151,87$ & $25.665,59$ & 17,78 & 16,21 & DECREASED \\
\hline LONG-TERM HOSPITALIZATION & $195.750,10$ & $26.194,78$ & $1.290,60$ & 540,43 & DECREASED \\
\hline DAILY HOSPITAL CARE & $9.823,88$ & $19.546,51$ & 236,26 & 186,97 & DECREASED \\
\hline TEACHING & $80.692,25$ & $252.047,52$ & $6.777,77$ & $5.481,86$ & DECREASED \\
\hline RESEARCH & $325.831,12$ & $409.729,38$ & $17.082,05$ & $9.580,24$ & DECREASED \\
\hline Lapclin Vigileish & $963.829,06$ & $1.349 .095,59$ & $25.471,36$ & $16.178,76$ & DECREASED \\
\hline
\end{tabular}

Source: Research results.

(*) In R\$, prices in 2010.

(**) DE - Expense items with resources included in INI's budget.

n.a. - not applicable

Table 3. Cost-Effectiveness in the Distribution of Expenses of INI's Activities per IA: 2009

\begin{tabular}{|c|c|c|c|c|c|c|}
\hline & \multirow[b]{2}{*}{$\mathbf{R}, \mathbf{R T}$} & \multicolumn{5}{|c|}{ DE-year: 2009} \\
\hline & & Outpatient Clinic & Daily Hospital Care & $\begin{array}{c}\text { Long-term } \\
\text { Hospitalization }\end{array}$ & Teaching & Research \\
\hline \multirow{5}{*}{ 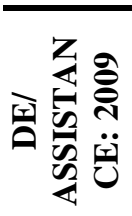 } & Outpatient Clinic & $0,31(\mathrm{RT})$ & - & - & - & - \\
\hline & Daily Hospital Care & - & $-0,02(\mathrm{R})$ & - & - & - \\
\hline & Long-term Hospitalization & - & - & $-0,45(\mathrm{R})$ & - & \\
\hline & Teaching & - & - & - & $0,52(\mathrm{RT})^{*}$ & \\
\hline & Research & - & - & - & - & $0,52(\mathrm{RT})^{*}$ \\
\hline
\end{tabular}

Source: Research results.

R, RT - Spearman's rank correlation coefficient, respectively with and without posts ties.

$*: \mathrm{p}<5 \%$

DE - Expense items with resources included in INI's budget. 
Finally, Figure 1 shows the overall assessment of INI's performance in all IAs from the perspective of efficiency analysis. Particularly, the effectiveness of activities undertaken by the LapClin Vigileish unit is analysed. The annual progress of relative technical efficiency synthesis scores of IAs and the synthetic performance score of LapClin Vigileish are shown. The figure allows the observation of variations in overall efficiency of IA during the period 2006-2009. Additionally, it shows that the efficiency gain of LapClin Vigileish was higher than that of all other IA.

Figure 1. INI and LapClin Vigileish - Relative Technical Efficiency Scores2006 to 2009

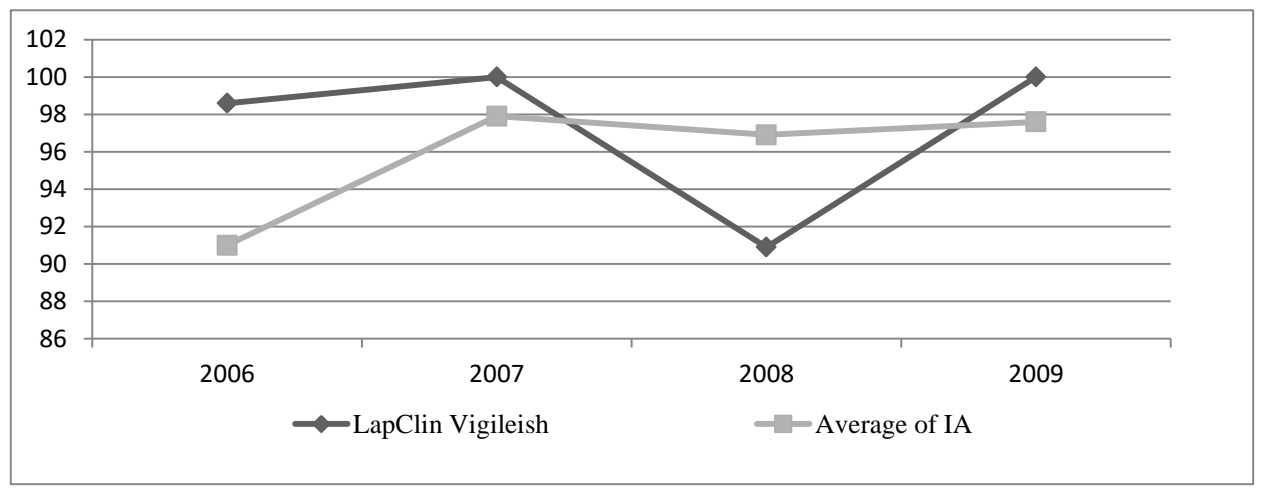

Source: Research results

\section{Discussion and Conclusions}

The main findings of the present study indicate that there were (a) costsaving innovations at all levels of clinical care in LapClin Vigileish, except in the outpatient clinic, in the period between 2006 and 2009; (b) proeffectiveness in motivation for resource distribution in clinical care, in terms of outpatient care and hospitalization, among all IA in 2009; and (c) stronger proefficiency motivation in LapClin Vigileish than in all other IA between 2006 and 2009.

As shown in tables 1 and 2, about 70 different types of clinical care procedures and 140 different types of diagnostic tests, as well as various expenses associated to research and teaching activities, reflect the diversification of healthcare assistance provided to LapClin Vigileish patients. This diversification appears to follow the pro-effectiveness principles stated in the comprehensive health care model in 2009. However, the overall value of DIE clinical care expenses per patient in 2010 prices (being equal to approximately $\mathrm{R} \$ 17,436$ as shown in table 1) is much lower compared to the threshold of cost-effective intervention, set by WHO to being equal to three times GDP per capita; namely, R\$ 54,108 in 2010 prices for Brazil (IBGE, 2016).

Previous assessments of the trial reported here compared the costs of medical care resources and diagnostic tests used in the treatment regimens with 
achieved treatment outcomes, reduction of adverse reactions and complications, and changes in laboratory indicators. These studies showed that there exist much more low-dosage treatment regimens on the efficiency frontier compared to high-dosage treatment interventions (Jorge et al. 2015).

Further, a recent study on LC treatment costs of LapClin Vigileish's clinical trial concluded that this bottom-up approach in setting a regulatory benchmark could support decision-making and promote innovation within the framework of a wider, multi-center experience for LTA treatment in Brazil (Schubach et al. 2015). Taken together, the findings of the present study and the conclusions reached in existing literature indicate that three primary concluding remarks regarding innovation efforts and outcomes can be made.

First, the hypothesis regarding cost-saving innovation is partially rejected, as average unit costs of the majority of patient-assistance services decreased along the levels of clinical attention in the cohort of patients in LapClin Vigileish between 2006 and 2009. However, outpatient care is the only exception, potentially requiring further investigation. Second, the hypothesis regarding innovation's orientation to cost-effectiveness is also partially rejected. Indeed, there exists a direct association between annual expenses and average unit costs in the following activities adopted by the IAs: outpatient clinical care, teaching and research. Therefore, it seems that the emphasis of decision-making is given to the "historic budget" criterion. Third, the relative technical efficiency synthesis score of LapClin Vigileish appears to be higher compared to the increasing average synthesis scores of performance of all other IAs during the period 2006-2009. Evidently, replacing the routine use of the standard treatment regimen with MA in LapClin Vigileish implemented in 2006 by the alternative schemes in 2009 , was motivated by the need to use specialized resources efficiently. Thus, the structure of this alternative intervention reflects efficient allocation of resources as one of the basic guiding principles of innovation.

The present study contributes in the literature on cost analysis of innovation by exploring two main issues. First, it examines jointly the hypothesis that innovation in multi-purpose public health organizations increases relative technical efficiency and the alternative assumption of costsaving innovation which increases cost effectiveness per activity. Second, it conducts efficiency analysis, using a data envelopment analysis model, to assess the economic rationality of innovation in the ATL treatment regimens, as implemented under phase III clinical trial in the LapClin Vigileish at INI.

Further, the main findings indicate that, despite the resources constraints that prevailed in the short run and postponed the diffusion of the new treatment to other labs, the strategic innovation in search of relative efficiency is quite effective and complies with the standards of the Comprehensive Health Care Model adopted in the Brazilian Unified Health System (SUS). These findings also highlight the merits of adopting the concept of efficiency analysis for assessing organizational effectiveness, both in the short run as well as in a strategic context. Certainly, analysing this quite specific and narrow case study hinders any generalization of the results, especially because efficiency analysis 
is limited to benchmarking among INI's own laboratories. However, a positive effect of innovation on LapClin Vigileish's performance has been observed, indicating that such innovations are potentially beneficial for health-care units. To conclude, the present study could serve as the basis for future studies on evaluation of performance of other multi-purpose organizations, allowing for international comparative analyses of various innovation efforts.

\section{References}

Birkinshaw J, Hamel G and Mol MJ (2008) Management innovation. Academy of Management Review 33(4): 825-845.

Bisang R and Katz J (1995) Reestructuracion Institucional y Bienes Públicos:El Caso de la Fundacion Instituto Oswaldo Cruz. Buneos Aires: Mimeografado.

Coelli T (1996) A guide to DEAP version 2.1: a data envelopment analysis (computer) program. CEPA Working Papers No. 8/96, University of New England, Australia, Centre for Efficiency and Productivity Analysis.

Coelli T, Rao DP, O'Donnell C and Battese G (2005) An introduction to efficiency and production analysis. Boston: Kluwer.

Djellal F and Gallouj F (1998) Mapping innovation dynamics in hospitals. Research Policy 34(6): 817-835.

Hasslocher-Moreno AM, Jorge MJ, Sousa ASd, Brasil, Pedro Emmanuel Alvarenga Americano do, Xavier SS, Barreto NdB, et al. (2013) Atenção integral e eficiência no Laboratório de Pesquisa Clínica em Doenças de Chagas do Instituto de Pesquisa Clínica Evandro Chagas, 2009-2011. Epidemiologia e Serviços De Saúde 22(2): 295-306.

Instituto Brasileiro de Geografia e Estatística. (2016). Brasil em síntese. Available at: http://brasilemsintese.ibge.gov.br/contas-nacionais/pib-per-capita.html

Jorge MJ, Carvalho FAd, Pimentel MIF and Salgueiro MdM (2015) Um Método Quantitativo para Incorporação da Dimensão Organizacional à Avaliação da Inovação na Organização Pública Multipropósito de Saúde. Revista ADM.MADE 19(2): 21-42.

Knaul FM, González-Pier E, Gómez-Dantés O, García-Junco D, Arreola-Ornelas H, Barraza-Lloréns M, et al. (2012) The quest for universal health coverage: achieving social protection for all in Mexico. The Lancet 380(9849): 1259-1279.

La Forgia GM and Couttolenc B (2008) Hospital Performance in Brazil: The Search for Excellence. Washington: World Bank Publications.

Mantri JK (2008) Research Methodology on Data Envelopment Analysis (DEA). Boca Raton, FL: Universal-Publishers.

Mintzberg H, Lample J, Quinn JB and Ghoshal S (2006) O processo da estratégia: conceitos, contextos e casos selecionados. $4^{\text {th }}$ ed. Porto Alegre: Bookman.

Nakagawa M (1994) ABC: Custeio Baseado Em Atividades. São Paulo: Atlas.

Oliveira-Neto MP, Schubach A, Mattos M, Goncalves-Costa SC and Pirmez C (1997) Treatment of American cutaneous leishmaniasis: a comparison between low dosage $(5 \mathrm{mg} / \mathrm{kg} /$ day $)$ and high dosage $(20 \mathrm{mg} / \mathrm{kg} /$ day $)$ antimony regimens. Pathologie-Biologie 45(6): 496-499.

Ozcan YA (2008) Health care benchmarking and performance evaluation: An Assessment using Data Envelopment Analysis (DEA). New York: Springer Science \& Business Media.

Romer PM (1994) The origins of endogenous growth. The Journal of Economic 
Perspectives 8(1): 3-22.

Rosenberg N (1976) Perspectives on Technology. Cambridge: Cambridge University Press

Ross CL (2009) Integral healthcare: the benefits and challenges of integrating complementary and alternative medicine with a conventional healthcare practice. Integrative Medicine Insights 4: 13-20.

SchubachAO, Marzochi KBF, Moreira JS, Schubach TMP, Araújo ML, Vale, Antônio Carlos Francesconi do, et al. (2005) Retrospective study of 151 patients with cutaneous leishmaniasis treated with meglumineantimoniate. Revista Da Sociedade Brasileira De Medicina Tropical 38(3): 213-217.

Schubach, AO, Jorge MJ, Pimentel MIF, Avellar AM, Avellar CM, Ferreira DS (2015) Benchmark Regulatório e Difusão da Inovação no Tratamento de Leishmanioses com Antimoniato de Meglumina no LAPCLINVIGILEISH/INI/Fiocruz. Estudo de Avaliação Descritiva. 19. LAPECOS/INI at Fiocruz.

Ulloa Gonzalez A and Barrantes Monge MC (2008) Bioética em Nicaragua. Acta Bioethica. 14 (2): 200-205. DOI: http://dx.doi.org/10.4067/S1726-569X2008000 200010

World Health Organization (2010) Control of the Leishmaniases: Report of a Meeting of the WHO Expert Committee on the Control of Leishmaniases. Geneva: World Health Organization. 